\title{
Gender-dependent association between sleep duration and overweight incidence in CHINESE school children: a national follow-up study
}

Muqing Cao ${ }^{1+}$, Yanna Zhu ${ }^{1+}$, Xiuhong $\mathrm{Li}^{1}$, Yajun Chen ${ }^{1}$, Jun Ma ${ }^{2^{*}}$ and Jin Jing ${ }^{1 *}$

\begin{abstract}
Background: The relationship between sleep duration and overweight risk remains unexplored among Chinese children. This study aims to evaluate this association in a national investigation with school-aged population.

Methods: There were 18,302 normal weight children in this Chinese national study which conducted during 2013-2014 included in the research. Anthropometric measurements were performed both at baseline and after 6-9 month. Sleep duration, physical activity, food intake and social economic information were collected by self-report questionnaire. Overweight was defined according to the updated Chinese criterion. Cox regression was used to evaluate the relationships between sleep duration and overweight incidence with multivariable adjusted.
\end{abstract}

Results: In total, there were 443 new overweight cases recorded at the end of observation. Overweight incidence with greater than $9 \mathrm{~h}$ (long sleep duration, LSD), 7 to $9 \mathrm{~h}$ (middle sleep duration, MSD), and less than $7 \mathrm{~h}$ of sleep (short sleep duration, SSD) were 2.7, 3.1 and 3.3\% respectively. Stratified by gender and compared with LSD, the hazard ratio (HR) of overweight for females with MSD was 1.60 (95\% Cl: 1.02-2.52). Stratified by age and gender, the HR in the group of MSD was $2.13(1.20-3.77)$ in female aged $6-10$ years and $0.24(0.06-0.93)$ in female aged 15-17 years.

Conclusion: The association between short sleep duration and overweight is age- and gender dependent. In group of small age and elder age, girls' adiposity states are independently associated with sleep duration. Sleep recommendation is a potential preventive action for overweight/obesity among girls.

Keywords: Overweight, Sleep duration, Gender, Age, Adolescents, Longitudinal study

\section{Background}

Sleep duration has decreased in the past few decades along with global modernisation [1]. Teenagers in the United States reportedly sleep for an average of less than $9 \mathrm{~h}$ in 2005 [2]. With rapid economic development and lifestyle changes, it is reasonable to speculate that the situation in China may be more severe. Based on regional

\footnotetext{
* Correspondence: majunt@bjmu.edu.cn; jingjin@mail.sysu.edu.cn

Dr. Yanna Zhu is the co-first author of this study.

${ }^{\dagger}$ Equal contributors

${ }^{2}$ Institute of Child and Adolescent Health, School of Public Health, Peking University Health Sciences Center, No. 38, Xueyuan Road, Haidian, 100191 Beijing, People's Republic of China

'Department of Maternal and Child Health, Faculty of Public Health, Sun Yat-sen University, No. 74, Zhongshan 2nd Road, Yuexiu, 510080 Guangzhou, People's Republic of China
}

(c) The Author(s). 2018 Open Access This article is distributed under the terms of the Creative Commons Attribution 4.0 International License (http://creativecommons.org/licenses/by/4.0/), which permits unrestricted use, distribution, and reproduction in any medium, provided you give appropriate credit to the original author(s) and the source, provide a link to the Creative Commons license, and indicate if changes were made. The Creative Commons Public Domain Dedication waiver (http://creativecommons.org/publicdomain/zero/1.0/) applies to the data made available in this article, unless otherwise stated.

data from 2013, half of Chinese teenagers failed to obtain $7 \mathrm{~h}$ of sleep per night, and $60 \%$ of Chinese primary school children sleep for less than $9 \mathrm{~h}$ [3]; however, no national data is available to describe China's situation.

Short sleep duration is associated with metabolic alternation [4], which promotes energy reservation [5] resulting in weight gain. For instance, short sleep duration was observed to increase ghrelin and decrease leptin releases, in which the former stimulates appetite and the latter restrains it. Consequently, these people tend to increase food consumption. In this case, the association between sleep and childhood obesity has been widely studied, most of which have indicated a negative association [6-9]. To investigate causality, longitudinal study should be adopted; 
however, most current studies have used cross-sectional data [10-12]. Hence, taking this longitudinal study to facilitate an in-depth understanding of the association between sleep and adiposity state could benefit children at risk.

Apart from obesity, overweight could also be a risk factor for negative health consequence [13]; however, few studies have mentioned the effect of short sleep on overweight risk. A link between no-rapid eye movement sleep and overweight was suggested, but the research has a relatively small sample size [14]. Moreover, child overweight, as the intermediate state between normal weight and obesity, could be reversed, which means it is worthy of exploration as an independent negative outcome. In addition, studies have usually focused on adults rather than children with rapid growth rate [15]. The sleep and weight standard recommendations for children are different [16], and thus, their adiposity states and sleep should be explored separately.

Sleep duration and adiposity states are influenced by several factors. Energy balance related behaviours such as physical activity, sedentary lifestyle and food intake [3] play an important role, which increases the complexity of the causality test [17]. With the use of China's regional data [3], we confirmed that short sleep duration could be an independent risk factor for childhood obesity, but a longitudinal research is still warranted to test causality.

In addition, adequate sleep duration decreases with ageing especially among children $[3,7]$. Thus, we speculate that the same sleep duration may have varying impact on the adiposity states of children with different ages. Unfortunately, information on age-specific effect is quite limited. Moreover, the requirements for daily sleep duration may also vary due to the different hormone levels of boys and girls [17]. In this case, the effect of sleep duration on adiposity states could differ among boys and girls.

Although the relationship between sleep duration and adiposity states has been extensively investigated in children, data on age- and gender-specific effects have remained limited and inconclusive [3, 18]. Given this background, we aim to describe the sleep duration among school-aged Chinese children and explore whether short sleep duration is an independent risk factor for the overweight and its potential gender- and age-specific effects. In this study, we investigated (i) the distribution sleep duration across age and (ii) the association between short sleep duration and overweight incidence in 9 months among different age and gender groups. For possible confounding factors, we adjusted physical activity/sedentary behaviour, dietary intake and social economic states.

\section{Methods}

\section{Participant enrolment}

Seven areas in China (Beijing, Tianjing, Liaoning, Ningxia, Shanghai, Changsha and Guangzhou) were chosen as research centres, which are considered representative in population geography for north (Beijing, Tianjing), northeast (Liaoning), northwest (Ningxia), east (Shanghai) , central (Changsha) and south (Guangzhou) part of China [19]. The recruitment of children and the survey of baseline information were described in the published protocol [19]. In this study, we enrolled 18,304 normal-weight children aged 6-17 years who agreed to participate in our national research and were assigned to the control group [19]. During the follow-up, a total of 4215 children still lacked information (missing data or unreached during the follow-up survey), and thus, the final sample was comprised 14,089 children. Compared with the remaining participants, those excluded from the study indicated no differences in age, percentage of males or baseline BMI. The study was approved by the Sun Yat-sen University Ethics Committee, and all parents/guardians of children signed the informed consent.

\section{Anthropometric measurement}

Each child underwent an anthropometric measurement which included height (centimetre, $\mathrm{cm}$ ) and weight (kilogram, kg) from September to November 2013. The detail of measurement procedure could be found in our previously published article [3]. The data on children that can be classified as overweight, obese, undernourished (Chinese criteria) [16] or suffering from obvious diseases or physical/mental deformities were excluded in the baseline analysis and follow-up.

\section{Questionnaire survey}

A standardised questionnaire was designed to collect demographic data (examination date, birth date, gender, mother's education level and monthly family income), puberty onset (whether a child has menstruation or spermatorrhea or not [20]), physical activity lifestyle (weekly hours of high- and middle-level physical activity, walking and sedentary) and dietary intake (daily intake of meat, sugar beverage, fruit and vegetable). The questionnaires were developed based on the information, motivation, and behavioural skills model [21] which was piloted and revised in the early stages of the project to be feasible for children/parents and teachers. The questionnaire was delivered to teachers in class during the week when anthropometric data were measured. Children were instructed to answer the questionnaire with their parents or guardians. Well-trained researchers ensured that the children would return the answered questionnaire to school. When all of the questionnaires were handed in, the researchers collected them from each class, and quality control was performed. Questionnaires that lacked five or more answers were returned to the children or their caregiver to have them answer the questions. In addition, there were $3 \%$ of the questionnaires rechecked 
within 1 week. We emphasised that the primary caregiver of the child should help answer the questionnaire considering their knowledge of the child.

The questionnaire items are described as follows:

The monthly family income was obtained by asking: "How much is your family's monthly income?" The monthly family income was categorised as $<5000$ and $>$ 5000 yuan, as well as unwilling to answer.

Mother's education years was derived by asking: "How many years did your mother spend in school?" Mother's education years was categorised as $\leq 9,10-12,13-16$ and $\geq 16$.

Puberty onset was obtained by asking: "Do you already have menstruation (female)/emission (male)?" Puberty onset was categorised as either Yes or No.

Sleep duration was determined by asking: "How many hours each night do you spend on sleeping?" Sleep duration was categorised as $<7,7-9$ and $\geq 9 \mathrm{~h}$ [7]

\section{Daily food intake}

Fruit intake was obtained by asking: "How many servings of fruit do you usually eat each day? One serving of fruit is equivalent to the size of an adult fist. If you are unsure about the size of an adult fist, then please check the last page of the questionnaire."

Vegetable intake was derived by asking: "How many servings of vegetables do you usually eat each day? One serving of vegetable is equivalent to the size of an adult's fist. If you are unsure about the size of an adult fist, then please check the last page of the questionnaire."

Sugar beverage consumption was determined by asking: "How many servings of sugar beverages do you usually take each day? One serving of sugar beverage is 250 millilitres." Sugar beverage includes juice with sugar, soda (e.g. Coca-cola), milk drinks, energy drinks (e.g. Red Bull) and other beverages that contain sugar.

Meat intake was obtained by asking: "How many servings of meat do you usually eat each day? A serving of meat is equivalent to the size of an adult palm. If you are unsure about the size of adult palm, then please see the last page of the questionnaire."

\section{Daily physical activity and sedentary behaviour}

High-level physical activity (HLPA) was obtained by asking: "How many hours each day do you usually do high-level physical activity? High-level physical activity refers to activities that cause people to experience extreme exhaustion, including basketball and football, as well as carrying a heavy load."

Middle-level physical activity (MLPA) was determined by asking: "How many hours each day do you usually have middle-level physical activity? Middle-level physical activity means activities that cause people to mildly perspire and experience slight exhaustion, for example, bicycling, playing table tennis and badminton, but not walking."

Walking was derived by asking: "How many hours each day do you usually walk? Walking includes those that occurred at school and home, commuting between school and home and merely for exercise."

Sedentary behaviour was assessed by the question: "How many hours each week do you sit or lie down at school and home (excluding sleeping)?”

\section{Follow-up data collection and definitions of overweight}

Follow-up data were collected from May to June 2014. The height and weight of the baseline normal-weight children were measured as described above. BMI was calculated by dividing weight in kilograms by height in meter squared $\left(\mathrm{kg} / \mathrm{m}^{2}\right)$. Overweight was defined according to the latest Chinese criteria [16].

\section{Statistical analysis}

We used EpiData 3.0 software (EpiData Association, Odense, Denmark) for data input and Statistical Package for the Social Sciences (SPSS, version 22.0, IBM Corporation, New York) to analyse data. Descriptive statistics were calculated for continuous (presented as mean values and standard errors) and categorical variables (presented as proportions). Chi-square tests were carried out for the differences of categorical variables. For continuous variables, the general linear model was used to evaluate differences among sleep duration groups, and LSD tests were performed for post hoc comparison between groups. The risk of overweight was evaluated using Cox regression models initially adjusted for age and gender in Model 1, and then puberty onset, dietary intake, physical activity and sedentary behaviour, mother's education and monthly family income were subsequently introduced into Model 2. The cluster data from the seven study areas were also introduced into the model, and a robust standard error was used to minimise the effect that the data may have obtained from different areas. The results were reported using hazard ratios (HRs) and corresponding 95\% confidence intervals (CIs). $P$ values of less than 0.05 were considered statistically significant. All the figures were prepared with Graph Pad 6.0 (La Jolla, CA, USA).

\section{Results}

\section{Baseline characteristics of the study population}

The baseline sample comprised of 18,302 normal-weight children (47\% males). The baseline characteristics of the participants are described in Table 1. Compared with females, males indicated higher mean values in height, weight, BMI, daily intake of foods (fruit, meat and sugar beverages) and physical activity (all $p<0.001$, Table 1 ), but lower mean value in sedentary behaviour $(p<0.001$, Table 1). In total, $18.3 \%$ of the participants reported a 
Table 1 Baseline characteristics among children aged 6-17 years in urban Guangzhou, China

\begin{tabular}{|c|c|c|c|c|}
\hline & Total & Boys & Girls & $P$ value \\
\hline \multicolumn{5}{|l|}{ Demographics } \\
\hline No. of participants & 18,302 & 8624 & 9678 & - \\
\hline Age (years) & $11.32(3.16)$ & $11.29(0.04)$ & $11.49(0.04)$ & 0.001 \\
\hline From Northern area (\%) & 40.4 & 40.5 & 40.2 & $<0.001$ \\
\hline Monthly income of Family (\%) & & & & 0.012 \\
\hline$\leq 5000$ yuan & 30.5 & 29.8 & 31.0 & \\
\hline$>5000$ yuan & 13.9 & 13.5 & 14.4 & \\
\hline Not willing to answer & 55.6 & 56.7 & 54.6 & \\
\hline Mother's education year (\%) & & & & 0.01 \\
\hline$\leq 9$ & 43.7 & 55.0 & 51.9 & \\
\hline $10-12$ & 20.4 & 25.6 & 25.6 & \\
\hline $13-16$ & 11.9 & 11.0 & 12.6 & \\
\hline$\geq 16$ & 9.8 & 9.8 & 9.8 & \\
\hline Puberty on-set (\%) & 56.1 & 43.4 & 65.2 & $<0.001$ \\
\hline Height(cm) & $147.26(16.12)$ & $148.95(0.22)$ & 146.93(0.21) & $<0.001$ \\
\hline Weight(kg) & $39.46(12.57)$ & $40.56(0.17)$ & $39.29(0.16)$ & $<0.001$ \\
\hline BMI & $17.73(2.26)$ & $17.65(0.03)$ & $17.73(0.03)$ & 0.078 \\
\hline \multicolumn{5}{|l|}{ Dietary intake (servings/day) } \\
\hline Fruit & $1.27(1.06)$ & $1.25(0.01)$ & $1.30(0.01)$ & 0.006 \\
\hline Vegetable & $1.79(1.40)$ & $1.81(0.02)$ & $1.79(0.02)$ & 0.27 \\
\hline Meat & $1.17(1.21)$ & $1.32(0.02)$ & $1.02(0.02)$ & $<0.001$ \\
\hline Sugar beverage & $0.41(0.74)$ & $0.50(0.01)$ & $0.33(0.01)$ & $<0.001$ \\
\hline \multicolumn{5}{|l|}{ Physical Activity (PA) } \\
\hline HLPA (hour/day) & $0.47(0.69)$ & $0.61(0.01)$ & $0.45(0.01)$ & $<0.001$ \\
\hline MLPA (hour/day) & $0.48(0.72)$ & $0.53(0.01)$ & $0.44(0.01)$ & $<0.001$ \\
\hline Walking (hour/day) & $0.78(1.13)$ & $0.84(0.02)$ & $0.74(0.02)$ & $<0.001$ \\
\hline Sedentary (hour/week) & $39.38(25.72)$ & $38.40(0.35)$ & $40.05(0.02)$ & $<0.001$ \\
\hline \multicolumn{5}{|l|}{ Sleep duration (\%) } \\
\hline$<7 \mathrm{~h}$ & 18.3 & 16.8 & 19.6 & $<0.001$ \\
\hline $7-9 h$ & 57.3 & 57.8 & 56.9 & \\
\hline$>9 h$ & 24.4 & 25.4 & 23.5 & \\
\hline
\end{tabular}

Continuous variables are displayed as mean (standard error, for boys and girls) and mean (standard deviation, for total), categorical variables are displayed as proportion. $P$ values are from T-tests (continuous variables) and chi-square tests (categorical variables) between boys and girls

$B M I$ body mass index, PA physical activity, HLPA high level physical activity, MLPA middle level activity

sleep duration of less than $7 \mathrm{~h}$ (short sleep duration, SSD), whereas $24.4 \%$ reported over $9 \mathrm{~h}$ (long sleep duration, LSD) daily. More females reported SSD than males $(P<0.01$; Table 1$)$. The trend showed that Chinese normal-weight children tended to have less sleep hours as they grow up (Fig. 1).

\section{Sample characteristic across sleep duration groups}

The median follow-up time was 225 days. A total of 4215 participants were excluded due to lack of follow-up information (23.0\%; no difference was found in age, gender, puberty onset, and distribution of sleep duration at baseline), whereas14,089 participants were included in the final analysis. The characteristics across the sleep duration of the participants, such as demography, dietary intake, physical activity/sedentary behaviour, anthropometry and incidence of overweight, are described in Table 2. Compared with children with LSD, participants with middle sleep duration (MSD, 7-9 h/night) and SSD indicated increased age, height, weight, BMI and puberty onset prevalence (all $p<0.05$, Table 2). For physical activity/ sedentary time, SSD and MSD children indicated decreased HPLA and MLPA but increased sedentary time compared with LSD children (all $p<0.05$, Table 2). For dietary intake, 

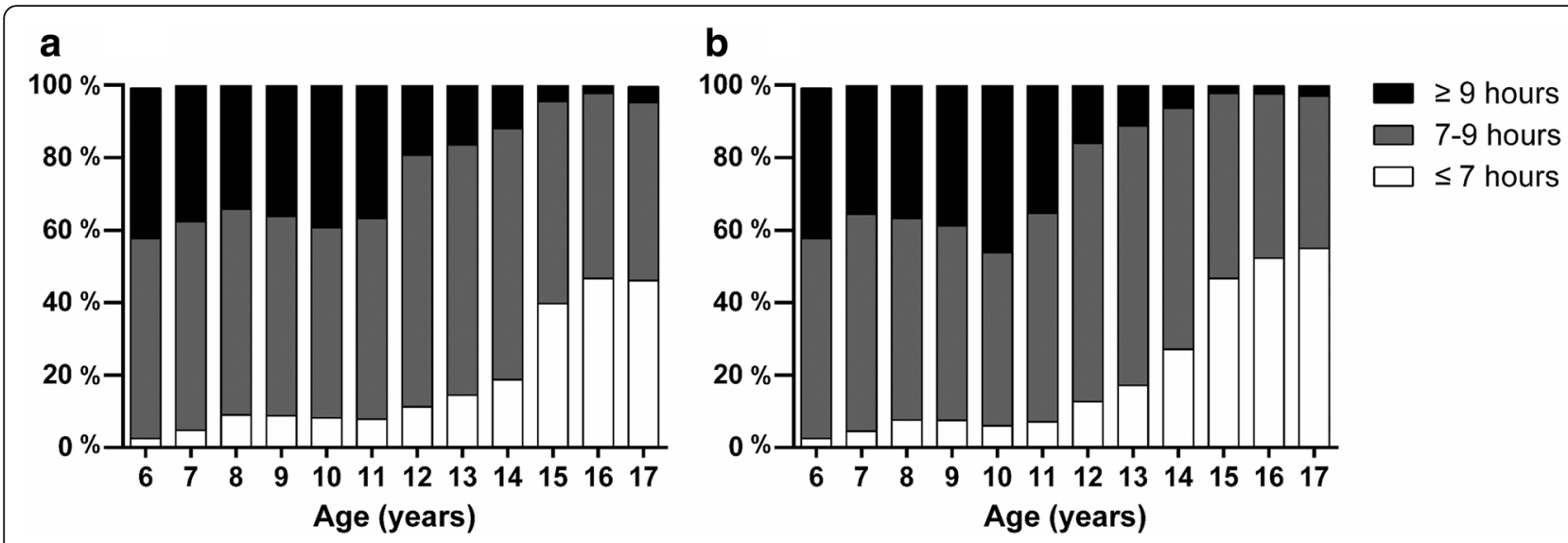

Fig. 1 Distribution of sleep duration among normal-weight Chinese males (a) and females (b) aged 6-17 years

SSD and MSD children reported increased meat and sugar beverage intake but decreased fruit and vegetable intake (all $p<0.05$, Table 2). A total of 443 new overweight cases were recorded (3.1\%), although no new obesity case was observed. Overweight incidents with LSD, MSD and SSD were 2.7, 3.1 and $3.3 \%$, respectively.

\section{Risks for overweight incidence among different sleep duration groups}

Based on sleep duration, the HRs for the overweight participants are summarized in Table 3. After adjusting for all confounding factors (age, sex, physical activity/ sedentary behaviour, dietary intake, mother's education level and monthly family income), as stratified by gender, females in the MSD group indicated a 1.60-fold risk of overweight incidence (95\% CI: 1.02-2.52) compared with those in the LSD group.

Based on the different puberty on-set age between female and male [22], we further stratified the sample by different age groups, females (aged 6-10 years) with MSD reported a 2.13-fold risk of overweight incidence (1.20-3.77; Table 3) compared with their counterparts in the LSD group. For elder adolescent (aged 15-17 years) females in the MSD group, the risk for overweight is $0.24(0.06-0.93$, Table 3) compared with those in the LSD group.

\section{Discussion}

We revealed that insufficient sleep was fairly common among Chinese normal-weight children using a national follow-up study. At 6 years old, nearly $60 \%$ of boys and girls failed to obtain $9 \mathrm{~h}$ sleep per night, which was even worse among older ones. The association between sleep duration and overweight is dependent on children's age and gender. For females, sleep duration between 7 and $9 \mathrm{~h}$ increases the risk of being overweight among those aged 6-10 year but decreases the risk for those aged 15-17 years (both compared with more than 9 h sleep). However, male's sleep duration is not independently associated with the overweight incidence in each age group.

The decrease of sleep duration has recently become an international epidemic [23]. Based on the US recommendation, the optimal sleep duration for children should be over $9 \mathrm{~h}$ per night [24-26]. However, our study reported that $75 \%$ of children slept for less than $9 \mathrm{~h}$ (Table 1 and Fig. 1). This result was in accordance with China's regional data that included normal weight and overweight/obesity children [3], but higher than the $44 \%$ reported by Spain in 2011 [27] and 11.1\% reported by UK in 2015 [28]. On the one hand, the observed discrepancies may be explained by the academic burden which Chinese children generally have [29]; on the other hand, the population of our research included primary school children and adolescents, in which the latter delayed the sleep phase and retained an early school time [30]. As we observed, no previous studies have reported on the sleep time of normal weight children either in China or in other countries; however, these children usually report less sleep problems such as sleep apnea. Hence, we speculate that the prevalence of insufficient sleep could be slightly higher if we included children with overweight and obesity at the baseline.

Previous research from several other countries has also reported that short sleep duration is a risk factor for obesity and a high BMI-Z score [9], which is also mediated by other behaviour factors such as sedentary lifestyle [31], physical activity level and food intake [32]. However, the inner mechanism is still unclear, although most studies have tended to believe short sleep duration led to a combination of increased food intake and sedentary habits [33]. We observed less physical activity and more sedentary behaviour and sugar beverage intake in this study (Table 2), which supported the hypothesis mentioned above.

A few studies have explored sleep duration, as well as overweight and obesity from a gender-specific perspective $[33,34]$. For instance, several studies have suggested that 
Table 2 Baseline characteristics according to sleep duration among normal weight children aged 6-17 years

\begin{tabular}{|c|c|c|c|c|}
\hline Characteristic & $>9 \mathrm{~h}$ & $7-9 \mathrm{~h}$ & $<7 \mathrm{~h}$ & $P$ for difference \\
\hline \multicolumn{5}{|l|}{ Age group } \\
\hline Before adolescents (male: 6-11 years, female:6-10 years) & 2947 & 4293 & 551 & $<0.001$ \\
\hline Young adolescents (male: 12-15 years, Female: 11-14 years) & 643 & 3044 & 823 & \\
\hline Elder adolescents (male: 15-17 years, Female: 16-17 years) & 76 & 1285 & 1382 & \\
\hline \multicolumn{5}{|l|}{ Demographics } \\
\hline No. of participants & 3666 & 8622 & 2756 & \\
\hline Male (\%) & 48.0 & 46.4 & 42.2 & $<0.001$ \\
\hline Age (years) & $9.64(0.06)$ & $11.37(0.04)$ & $13.53(0.07)$ & $<0.001$ \\
\hline From Northern area (\%) & 36.8 & 37.2 & 39.7 & $<0.001$ \\
\hline Monthly income of Family (\%) & & & & $<0.001$ \\
\hline$\leq 5000$ yuan & 24.0 & 60.1 & 15.9 & \\
\hline$>5000$ yuan & 26.7 & 58.9 & 14.5 & \\
\hline Not willing to answer & 23.9 & 55.0 & 21.0 & \\
\hline Mother's education year (\%) & & & & $<0.001$ \\
\hline$\leq 9$ & 24.4 & 59.1 & 16.5 & \\
\hline $10-12$ & 25.5 & 59.5 & 15.0 & \\
\hline $13-16$ & 27.6 & 58.9 & 13.4 & \\
\hline$\geq 16$ & 29.2 & 56.1 & 14.7 & \\
\hline Puberty on-set (\%) & 8.0 & 27.5 & 59.0 & $<0.001$ \\
\hline \multicolumn{5}{|l|}{ Lifestyle } \\
\hline \multicolumn{5}{|l|}{ Physical activity(PA) } \\
\hline High-level PA (hour/day) & $0.56(0.14)$ & $0.52(0.01)$ & $0.52(0.02)$ & $<0.001$ \\
\hline Middle-level PA (hour/day) & $0.56(0.02)$ & $0.47(0.01)$ & $0.46(0.02)$ & $<0.001$ \\
\hline Walking (hour/day) & $0.80(0.02)$ & $0.76(0.02)$ & $0.83(0.03)$ & $<0.001$ \\
\hline Sedentary (hour/week) & $34.70(0.52)$ & $40.03(0.33)$ & $45.42(0.62)$ & $<0.001$ \\
\hline \multicolumn{5}{|l|}{ Dietary intake(serve/day) } \\
\hline Meat & $1.14(0.02)$ & $1.17(0.02)$ & $1.25(0.03)$ & $<0.001$ \\
\hline Sugar beverage & $0.29(0.02)$ & $0.41(0.01)$ & $0.56(0.02)$ & $<0.001$ \\
\hline Fruit & $1.43(0.02)$ & $1.26(0.01)$ & $1.21(0.03)$ & $<0.001$ \\
\hline Vegetable & $1.94(0.03)$ & $1.79(0.02)$ & $1.71(0.03)$ & $<0.001$ \\
\hline \multicolumn{5}{|l|}{ Anthropometry } \\
\hline Height (cm) & $139.77(0.31)$ & $148.07(0.20)$ & 156.82(0.363) & $<0.001$ \\
\hline Weight (kg) & $33.22(0.24)$ & $39.93(0.15)$ & $47.43(0.28)$ & $<0.001$ \\
\hline BMl & $16.65(0.05)$ & $17.70(0.03)$ & $18.86(0.05)$ & $<0.001$ \\
\hline
\end{tabular}

Continuous variables are displayed as mean (standard error), categorical variables are displayed as proportion

$P$ values are from T-tests (continuous variables) and chi-square tests (categorical variables) between boys and girls

$B M I$ body mass index, PA physical activity, HLPA high level physical activity, MLPA middle level activity

the effect of sleep duration on obesity was only present in females with considerable sleep debt [35]. In our study, increased risks of being overweight were observed only for females who slept for 7-9 h after multivariable adjustment (Table 2). In addition, the trend showed increased overweight risk for females with $<7$ h sleep (although the statistic power compromised by a relative low sample size, as indicated in Table 3), which proved the gender specific phenomenon mentioned above [36]. Females reportedly need less sleep [36], and they may show different behaviour pattern for energy balance. Males have more physical activities and less sedentary behaviours (Table 1), which could evidently prevent them from being overweight; moreover, the higher basic metabolic rate of males compared with females increases energy expenditure [37], which could be a protective factor for overweight and obesity. In this case, the adiposity state may not be so sensitive to the short sleep decline among males relative 
Table 3 HRs for overweight incidence according to sleep duration group among Chinese normal weight children in 6-9 months follow-up

\begin{tabular}{|c|c|c|c|c|}
\hline Group & No. of Participants & No. of new overweight & Model $1^{a}$ & Model $2^{b}$ \\
\hline \multicolumn{5}{|l|}{ Male } \\
\hline$>9 h$ & 1735 & 47 & 1 & 1 \\
\hline $7-9 \mathrm{~h}$ & 3950 & 112 & $1.09(0.77-1.54)$ & $1.03(0.67-1.59)$ \\
\hline$<7 \mathrm{~h}$ & 855 & 38 & $1.38(0.87-2.21)$ & $1.21(0.65-2.24)$ \\
\hline \multicolumn{5}{|l|}{ Female } \\
\hline$>9 h$ & 1888 & 46 & 1 & 1 \\
\hline $7-9 \mathrm{~h}$ & 4563 & 140 & $1.23(0.87-1.74)$ & $1.60(1.02-2.52)^{*}$ \\
\hline$<7 \mathrm{~h}$ & 1667 & 50 & $1.28(0.81-2.00)$ & $1.71(0.95-3.08)$ \\
\hline \multicolumn{5}{|c|}{ Stratified by age and gender } \\
\hline \multicolumn{5}{|c|}{ Before adolescents } \\
\hline \multicolumn{5}{|c|}{ Male (6-11 years) } \\
\hline$>9 \mathrm{~h}$ & 1416 & 43 & 1 & 1 \\
\hline $7-9 h$ & 2148 & 66 & $1.04(0.71-1.53)$ & $1.05(0.65-1.70)$ \\
\hline$<7 \mathrm{~h}$ & 302 & 7 & $0.84(0.38-1.86)$ & $0.84(0.29-2.40)$ \\
\hline \multicolumn{5}{|c|}{ Female (6-10 years) } \\
\hline$>9 h$ & 1499 & 34 & 1 & 1 \\
\hline $7-9 h$ & 2086 & 64 & $1.41(0.93-2.13)$ & $2.13(1.20-3.77)^{*}$ \\
\hline$<7 \mathrm{~h}$ & 247 & 8 & $1.46(0.68-3.16)$ & $1.78(0.65-4.87)$ \\
\hline \multicolumn{5}{|c|}{ Young adolescents } \\
\hline \multicolumn{5}{|c|}{ Male (12-15 years) } \\
\hline$>9 h$ & 287 & 3 & 1 & 1 \\
\hline $7-9 \mathrm{~h}$ & 1411 & 34 & $2.14(0.65-7.01)$ & $1.41(0.41-4.87)$ \\
\hline$<7 \mathrm{~h}$ & 450 & 17 & $3.58(1.02-12.49)^{*}$ & $2.19(0.56-8.51)$ \\
\hline \multicolumn{5}{|c|}{ Female (11-14 years) } \\
\hline$>9 h$ & 346 & 7 & 1 & 1 \\
\hline $7-9 h$ & 1595 & 44 & $1.12(0.50-2.52)$ & $1.31(0.49-3.47)$ \\
\hline$<7 \mathrm{~h}$ & 366 & 12 & $1.31(0.50-3.40)$ & $1.28(0.38-4.28)$ \\
\hline \multicolumn{5}{|c|}{ Elder adolescents } \\
\hline \multicolumn{5}{|c|}{ Male (15-17 years) } \\
\hline$>9 \mathrm{~h}$ & 32 & 1 & 1 & 1 \\
\hline $7-9 h$ & 391 & 12 & $1.42(0.18-10.98)$ & $0.36(0.04-3.46)$ \\
\hline$<7 \mathrm{~h}$ & 405 & 14 & $1.87(0.24-14.40)$ & $0.28(0.03-2.89)$ \\
\hline \multicolumn{5}{|c|}{ Female (16-17 years) } \\
\hline$>9 \mathrm{~h}$ & 43 & 5 & 1 & 1 \\
\hline $7-9 h$ & 882 & 32 & $0.50(0.19-1.29)$ & $0.24(0.06-0.93)^{*}$ \\
\hline$<7 \mathrm{~h}$ & 970 & 30 & $0.53(0.20-1.37)$ & $0.28(0.07-1.12)$ \\
\hline
\end{tabular}

HRs hazard ratios, risk for overweight are displayed as $\mathrm{HR}(95 \% \mathrm{Cl})$

${ }^{*} \mathrm{P}<0.05$ compared with '> $9 \mathrm{~h}$ ' group

a Model 1 was adjusted for age

${ }^{\mathrm{b}}$ Model 2 was adjusted Model 1 covariates plus puberty on-set, food intake, physical activity\& sedentary, domestic income and mother's year of education

to females. Furthermore, we also found reversed relationship between adiposity states and sleep duration among boys in our previous study [3], which also supports our results. In addition, the risk of overweight among females is observed when mother's education and family income were adjusted (Table 3), which means that the social hierarchy of children depends on their sleep duration. This result is in line with those of previous studies [12]. A study in Japanese adults indicated that the association existed only in males [38]; however, it had limitation that 
the confounders in the study did not include behaviour. Although in our study a negative association among young adolescent males was observed (Table 2 and Model 1), but it tended to be insignificant after physical activity, food intake and social economic factor were included (Table 3 and Model 2). In this case, the association between sleep duration and overweight could be mediated by behaviour among males [38] rather than independent.

Stratified by age group, research has found that short sleep increased BMI [34] only in adolescent female. By contrast, we observed increased risk for overweight among before adolescence girls but decreased risk among elder adolescence girls with MSD (Table 3). The discrepancy among age groups may be attributed to the difference of age groups and the definition of short sleep first and second to declining biological sleep duration with age [39]. Although sleep recommendation for children is $9 \mathrm{~h}$, it is well recognised that 6 -year old children require more sleep than 17 years old [40],sleep duration declines naturally with age and puberty onset [30]. In addition, studies have indicated that long and short sleep duration increased the risk of overweight and obesity [7]. Moreover, it is reported that female sleep less than males [41]. Thus, the optimal sleeping hours for post-puberty females, which is less than $9 \mathrm{~h}$, is possible, and 7-9 h sleep could be suitable for elder adolescent girls.

This study included some limitations. Sleep duration was self-reported, which sometimes could be the ideal sleep duration that the participants thought they had other than their actual sleep duration. In addition, nearly $23 \%$ of the participants failed to complete the follow-up procedure. Considering that overweight children may refuse to be weighed, the excluded subjects may have a higher rate of obesity. Bedtimes have been found to be associated with obesity independent of sleep duration [42]; however, we did not include this factor in the study. An objective technique is considerably useful in conducting sleep research in the future. The exclusion of self-report bias is generally deemed to be the optimal approach. Considering that we used a questionnaire that has neither been statistically validated nor tested for reliability; thus, potential bias cannot be excluded.

\section{Conclusion}

In this study, we showed that sleep duration among normal-weight Chinese children decreased with age. For 6-10-year-old females, 7-9 h of sleep increased the risk of overweight relative to more than $9 \mathrm{~h}$ of sleep. However, the same sleep duration may decrease the risk for females aged 15-17 years, and males may not be as susceptible as their counterparts to the effect of sleep duration change in the adiposity state. For the purpose of obesity intervention, an age- and gender-specific sleep duration recommendation for children is warranted.

\section{Abbreviations}

BMI: Body mass index; LSD: Long sleep duration; MSD: Middle sleep duration; SSD: Short sleep duration

\section{Acknowledgements}

We thank all the children and their parents who willingly participated in the national survey. We also appreciate all the doctors from the middle and primary schools who performed anthropometric measurements and the postgraduate students who helped with the questionnaire survey and data input.

\section{Funding}

This study was supported by a national health foundation named "annual special research of the health industry (2012, No. 201202010)" which was provided by Ministry of Health, China,as well as "An intervention study for sleep behaviour of school aged autism children (2018, No. A2018136)," which was provided by Ministry of Health, Guangdong Province, China. This research uses data from "Students Major Disease Prevention \& Control Technology and Its Development and Application" (1147 Project, No. 201202010). Opinions represent those of the authors and do not necessarily reflect those of the granting agencies.

\section{Availability of data and materials}

The datasets generated and/or analysed during the current study are not publicly available due to the funding policy but are available from the corresponding author on reasonable request.

\section{Authors' contributions}

$M C, Y Z$ and JJ concepted and designed the study; MC, $X L$ and $Y C$ analysed and interpreted the data; MC, YZ, JM and JJ had important intellectual input in drafting or revising the manuscript. All authors read and approved the final manuscript.

\section{Ethics approval and consent to participate}

The study was approved by the Sun Yat-sen University Ethics Committee, and all the parents/guardians of children signed the informed consent.

\section{Competing interests}

The authors declare that they have no competing interests.

\section{Publisher's Note}

Springer Nature remains neutral with regard to jurisdictional claims in published maps and institutional affiliations.

Received: 12 October 2017 Accepted: 17 April 2018

Published online: 11 May 2018

References

1. Van Cauter E, Knutson KL. Sleep and the epidemic of obesity in children and adults. Eur J Endocrinol. 2008;159(Suppl 1):S59-66.

2. Drobnich D. A National Sleep Foundation's conference summary: the National Summit to prevent drowsy driving and a new call to action. Ind Health. 2005;43(1):197-200.

3. Cao M, Zhu Y, He B, Yang W, Chen Y, Ma J, Jing J. Association between sleep duration and obesity is age- and gender-dependent in Chinese urban children aged 6-18 years: a cross-sectional study. BMC Public Health. 2015. 15:1029.

4. Lee MS, Song J, Kim H, Park K, Moon S. Effect of multi-functional fabric on sleep stages and growth hormone levels during sleep. Int J Neurosci. 2004; 114(7):795-804.

5. Spaeth AM, Dinges DF, Goel N. Objective measurements of energy balance are associated with sleep architecture in healthy adults. Sleep. 2016;

6. Bayon V, Leger D, Gomez-Merino D, Vecchierini M, Chennaoui M. Sleep debt and obesity. Ann Med. 2014;46(5):264-72.

7. Shi Z, Taylor AW, Gill TK, Tuckerman J, Adams R. Short sleep duration and obesity among Australian children. BMC Public Health. 2010;10:609.

8. Chaput JP, Lambert M, Gray-Donald K, McGrath JJ, Tremblay MS, O'Loughlin J, Tremblay A. Short sleep duration is independently associated with overweight and obesity in Quebec children. Can J Public Health. 2011; 102(5):369-74 
9. Zimberg IZ, Dâmaso A, Del Re M, Carneiro AM, Sá Souza H, Lira FS, Tufik S, Mello MT. Short sleep duration and obesity: mechanisms and future perspectives. Cell Biochem Funct. 2012;30(6):524-9.

10. Cepeda MS, Stang P, Blacketer C, Kent JM, Wittenberg GM. Clinical relevance of sleep duration: results from a cross-sectional analysis using NHANES. J Clin Sleep Med. 2016;12(06):813-9.

11. Thasanasuwan W, Srichan W, Kijboonchoo K, Yamborisut U, Wimonpeerapattana W, Rojroongwasinkul N, Khouw IT, Deurenberg P. Low sleeping time, high TV viewing time, and physical inactivity in school are risk factors for obesity in pre-adolescent Thai children. J Med Assoc Thail. 2016;99(3):314-21.

12. Quach J, Price AMH, Bittman M, Hiscock H. Sleep timing and child and parent outcomes in Australian 4-9-year-olds: a cross-sectional and longitudinal study. Sleep Med. 2016;22:39-46.

13. Miller LA, Grunwald GK, Johnson SL, Krebs NF. Disease severity at time of referral for pediatric failure to thrive and obesity: time for a paradigm shift? J Pediatr. 2002;141(1):121-4.

14. Pacheco SR, Miranda AM, Coelho R, Monteiro AC, Bragança G, Loureiro HC Overweight in youth and sleep quality: is there a link? Arch Endocrinol Metab. 2017;61(4):367-73.

15. Mezick EJ, Wing RR, McCaffery JM. Associations of self-reported and actigraphy-assessed sleep characteristics with body mass index and waist circumference in adults: moderation by gender. Sleep Med. 2014;15(1):64-70.

16. Li H, Zong XN, Ji CY, Mi J. Body mass index cut-offs for overweight and obesity in Chinese children and adolescents aged 2 - 18 years (in Chinese). Zhonghua Liu Xing Bing Xue Za Zhi. 2010;31(6):616-20.

17. Mostazir M, Jeffery A, Hosking J, Metcalf B, Voss L, Wilkin T. Evidence for energy conservation during pubertal growth. A 10-year longitudinal study (EarlyBird 71). Int J Obesity. 2016;40(11):1619-26.

18. Lim HH. Sleep duration independently influences metabolic body size phenotype in children and adolescents: a population-based study. Sleep Med. 2018:42:47-52

19. Chen Y, Ma L, Ma Y, Wang H, Luo J, Zhang X, Luo C, Wang H, Zhao H, Pan $D$, et al. A national school-based health lifestyles interventions among Chinese children and adolescents against obesity: rationale, design and methodology of a randomized controlled trial in China. BMC Public Health. 2015;15(1):210

20. James E, Wood CL, Nair H, Williams TC. Preterm birth and the timing of puberty: a systematic review. BMC Pediatr. 2018;18(1):3.

21. Fisher JD, Amico KR, Fisher WA, Harman JJ. The information-motivationbehavioral skills model of antiretroviral adherence and its applications. Curr HIV/AIDS Rep. 2008:5(4):193-203.

22. Hu Z, Chen R, Cai C. Association of genetic polymorphisms around the LIN28B gene and idiopathic central precocious puberty risks among Chinese girls. Pediatr Res. 2016;80(4):521-5.

23. Cappuccio FP, D'Elia L, Strazzullo P, Miller MA. Sleep duration and all-cause mortality: a systematic review and meta-analysis of prospective studies. Sleep. 2010;33(5):585-92.

24. Skelton JA. Family intervention focused on effective parenting is associated with decreased child obesity prevalence 3-5 years later. Evid Based Med. 2013;18(1):e5.

25. John B. Sleep-patterns, sleep hygiene behaviors and parental monitoring among Bahrain-based Indian adolescents. J Family Med Prim Care. 2015:4(2):232

26. Hirshkowitz M, Whiton K, Albert SM, Alessi C, Bruni O, DonCarlos L, Hazen N, Herman J, Katz ES, Kheirandish-Gozal L, et al. National Sleep Foundation's sleep time duration recommendations: methodology and results summary. Sleep Health. 2015;1(1):40-3.

27. de Ruiter I, Olmedo-Requena R, Sánchez-Cruz J, Jiménez-Moleón J. Changes in sleep duration in Spanish children aged 2-14 years from 1987 to 2011. Sleep Med. 2016;21:145-50

28. Bonuck K, Chervin RD, Howe LD. Sleep-disordered breathing, sleep duration, and childhood overweight: a longitudinal cohort study. J Pediatr. 2015; 166(3):632-9.

29. Jiang $X$, Hardy LL, Baur LA, Ding D, Wang L, Shi H. Sleep duration, schedule and quality among urban Chinese children and adolescents: associations with routine after-school activities. PLoS One. 2015:10(1):e115326.

30. Collings PJ, Wijndaele K, Corder K, Westgate K, Ridgway CL, Sharp SJ, Atkin AJ, Bamber D, Goodyer I, Brage S, et al. Prospective associations between sedentary time, sleep duration and adiposity in adolescents. Sleep Med. 2015:16(6):717-22
31. Magee C, Caputi P, Iverson D. Lack of sleep could increase obesity in children and too much television could be partly to blame. Acta Paediatr. 2014;103(1):e27-31.

32. Jalali-Farahani $\mathrm{S}$, Amiri $\mathrm{P}$, Chin YS. Are physical activity, sedentary behaviors and sleep duration associated with body mass index-for-age and healthrelated quality of life among high school boys and girls? Health Qual Life Outcomes. 2016;14(1):30

33. Garaulet M, Ortega FB, Ruiz JR, Rey-Lopez JP, Beghin L, Manios Y, CuencaGarcia M, Plada M, Diethelm K, Kafatos A, et al. Short sleep duration is associated with increased obesity markers in European adolescents: effect of physical activity and dietary habits. The HELENA study. Int J Obes. 2011 35(10):1308-17.

34. Ames ME, Holfeld B, Leadbeater BJ. Sex and age group differences in the associations between sleep duration and BMI from adolescence to young adulthood. Psychol Health. 2016:31(8):976-92.

35. Eisenmann J, Ekkekakis P, Holmes M. Sleep duration and overweight among Australian children and adolescents. Acta Paediatr. 2006;95(8):956-63.

36. Guidolin M, Gradisar M. Is shortened sleep duration a risk factor for overweight and obesity during adolescence? A review of the empirical literature. Sleep Med. 2012:13(7):779-86.

37. Kaneko K, Ito C, Koizumi K, Watanabe S, Umeda Y, Ishikawa-Takata K. Resting energy expenditure (REE) in six- to seventeen-year-old Japanese children and adolescents. J Nutr Sci Vitaminol (Tokyo). 2013;59(4):299-309.

38. Sun W, Yuan J, Yu Y, Wang Z, Shankar N, Ali G, Xie Y, Xu T, Shan G. Poor sleep quality associated with obesity in men. Sleep Breath. 2015;

39. Gadie A, Shafto $M$, Leng $Y$, Kievit RA. How are age-related differences in sleep quality associated with health outcomes? An epidemiological investigation in a UK cohort of 2406 adults. BMJ Open. 2017;7(7):e14920.

40. Ferrara M, De Gennaro L. How much sleep do we need? Sleep Med Rev. 2001;5(2):155-79.

41. Štefan L, Juranko D, Prosoli R, Bari R, Spori G. Self-reported sleep duration and self-rated health in young adults. J Clin Sleep Med. 2017;13(7):899-904.

42. Anderson SE, Andridge R, Whitaker RC. Bedtime in preschool-aged children and risk for adolescent obesity. J Pediatr. 2016;176:17-22

\section{Ready to submit your research? Choose BMC and benefit from:}

- fast, convenient online submission

- thorough peer review by experienced researchers in your field

- rapid publication on acceptance

- support for research data, including large and complex data types

- gold Open Access which fosters wider collaboration and increased citations

- maximum visibility for your research: over $100 \mathrm{M}$ website views per year

At BMC, research is always in progress.

Learn more biomedcentral.com/submissions 